\title{
Performance Analysis of Supercapacitor Integrated PV Fed Multistage Converter with SMC Controlled VSI for Different Load Conditions
}

\author{
Shruti Pandey ${ }^{1}$, Bharti Dwivedi ${ }^{2}$, Anurag Tripathi ${ }^{3}$ \\ Department of Electrical Engineering, Institute of Engineering and Technology, Lucknow, India
}

\begin{tabular}{|c|c|}
\hline Article Info & ABSTRACT \\
\hline Article history: & The proposed work comprises of an MPPT controlled Photovoltaic (PV) \\
\hline Received Sep 3, 2017 & $\begin{array}{l}\text { source, in conjunction with a supercapacitor, cascaded with a Sliding Mode } \\
\text { Controlled (SMC) Inverter, supplying variable nonlinear loads. The effects of }\end{array}$ \\
\hline Revised Feb 25, 2018 & varying solar irradiation and its intermittency have been effectively managed \\
\hline Accepted Mar 18, 2018 & $\begin{array}{l}\text { by the MPPT controlled boost converter and charge controlled supercapacitor } \\
\text { respectively. The charge controller bucks and boosts the terminal voltage and }\end{array}$ \\
\hline Keyword: & $\begin{array}{l}\text { realizes the power flow in a bidirectional manner. Seamless action has been } \\
\text { obtained by the proposed model under varying irradiation and for varying }\end{array}$ \\
\hline $\begin{array}{l}\text { Bidirectional converter } \\
\text { DC-DC boost converter } \\
\text { Mppt }\end{array}$ & $\begin{array}{l}\text { load conditions. The performance of the SMC controlled Inverter, when } \\
\text { compared with a PI controlled Inverter, has been found to be superior in } \\
\text { terms of power quality and robustness of the supply system }\end{array}$ \\
\hline
\end{tabular}

Photo voltaic

Sliding mode control

Supercapacitor

Voltage source inverter

Copyright $(2018$ Institute of Advanced Engineering and Science. All rights reserved.

\section{Corresponding Author:}

Shruti Pandey,

Departement of Electrical Engineering,

Institute of Engineering and Technology

Lucknow, India.

Email: shrutipandey@ietlucknow.ac.in

\section{INTRODUCTION}

The photo-voltaic (PV) system is the most admired energy source among all the existing renewable energy sources. In PV fed microgrid system Inverters are used at the load for various applications. In order to provide good class stabilized output whether it is in terms of steady state performance such as THD and voltage regulation or in terms of transient performance such as quick settlement against variations in supply and load, advanced strategies of control are needed to be deployed with Voltage source Inverters [1].

There are several strategies of voltage source inverter (VSI) control. Conventionally used PI control, which is incapable of tracking periodic signals. At the same time basic hysteresis current control that generates a variable switching frequency requiring application of appropriate filter with it. Multiple feedback loop control scheme with moderate switching frequency makes output voltage waveform purely sinusoidal [2] however, with non-linear loads it provides distorted output voltage.

All the above reported linear controllers work satisfactorily nearby equilibrium point only, to guarantee the global stability of the VSI system under large perturbations. By and large the non-linear controllers play better role. One of the frequently used non-linear controllers is Passivity-Based Control (PBC) [3,4]. However in PBC method, the global asymptotic stability is guaranteed with the perfect parameter match assumption which is not valid in practice and leads to steady-state error in the output voltage. Sliding Mode Control (SMC) is a non-linear control technique which is superior in terms of stability, simplicity, regulation and robustness under wide range of operating conditions [5]. The major advantage of 
SMC's performance against any disturbance in the system parameters or in the loads [6] is its fast tracking ability and better stabilization that help in developing high-performance of VSI circuits. [7,8]

The supercapacitor (or ultracapacitor) has acquired a wide attention as complementary source of power to PV systems due to its higher power density $(\mathrm{kW} / \mathrm{kg})$, longer life, larger charge and dischargecycles, lower equivalent series resistance, lesser heating losses and wider temperature range as against batteries [9, 10]. Lower voltage rating and varying terminal voltage issues of supercapacitor are handled satisfactorily with the use of a Bidirectional dc-dc converter which acts as a controlled charger allowing charging and discharging currents to flow to and from the supercapacitor as per the need.

\section{PROPOSED SYSTEM CONFIGURATION}

The schematic representation of proposed system is shown in Figure 1. The block diagram consists of a PV array with varying solar irradiation whose output is given to DC-DC boost converter, MPPT algorithm is used to track maximum power. Super capacitor is introduced with a suitable battery charger (DC-DC buck boost converter) to interface with Dc link of the inverter. Further the PI and SMC VSI converts the DC link power into a high quality ac power for feeding the loads for which it makes use of a PI or SMC controller.

Figure 2 shows a single phase Voltage Source Inverter for RL load, along with an RLC filter. The output of the Inverter is given by $\mathrm{V}_{0}$ and $\mathrm{U}$ is the control variable of the single phase inverter.

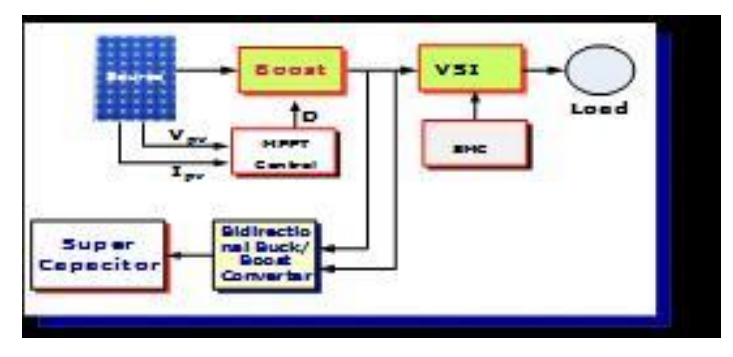

Figure 1. Block Diagram of Proposed Configuration

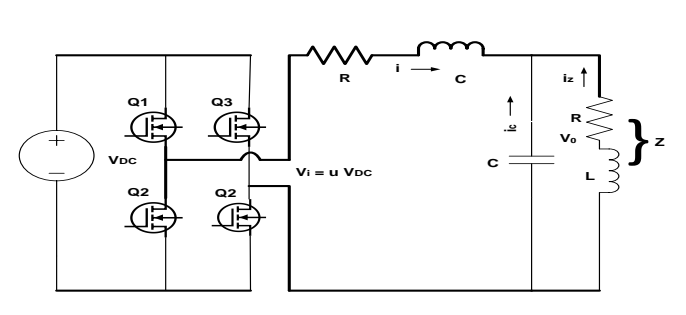

Figure 2. Inverter

The state space model of the inverter based on the state variables, given below, is used in the sliding surface in Sliding Mode Controller. Here $\mathrm{V}_{0}$ and $\mathrm{i}$ are the state variables.

$$
\begin{aligned}
& \dot{x}=F x+H u \\
& F=\left[\begin{array}{cc}
-\frac{1}{Z C} & \frac{1}{C} \\
\frac{-1}{L} & 0
\end{array}\right] \\
& H=\left[\begin{array}{c}
0 \\
\frac{V_{D C}}{L}
\end{array}\right]
\end{aligned}
$$

The output equation with $\mathrm{V}_{0}$ as output can be written as $C=\left[\begin{array}{ll}1 & 0\end{array}\right]$

\section{CONTROLLERS USED}

\subsection{MPPT Control}

Fixed type $\mathrm{P}$ and O MPPT is used here to make it easily implementable.In this particular MPPT algorithm $\Delta \mathrm{D}$ updating is done and in each step $\Delta \mathrm{D}$ is varied by $20 \mathrm{e}^{-6}$, Initial value for $\mathrm{D}=0.6$, upper limit for $\mathrm{D}(\mathrm{D} \max =0.9)$, lower limit of $\mathrm{D}(\mathrm{D} \min =0.02)$. 

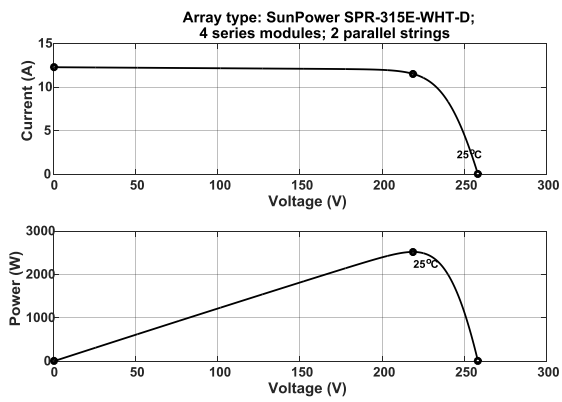

Figure 3. I-V and P-V Characteristics at $1000 \mathrm{~W} / \mathrm{m}^{2}$ and $25^{\circ} \mathrm{C}$

\subsection{Supercapacitor Charge Management Control}

Charging and discharging process of supercapacitor is performed in two steps. One is through constant current charging and the other is constant current discharging. [11] Control diagram of the constant current charging mode and constant current discharging mode.is shown in the Figure $4 \mathrm{a}$ and $4 \mathrm{~b}$.

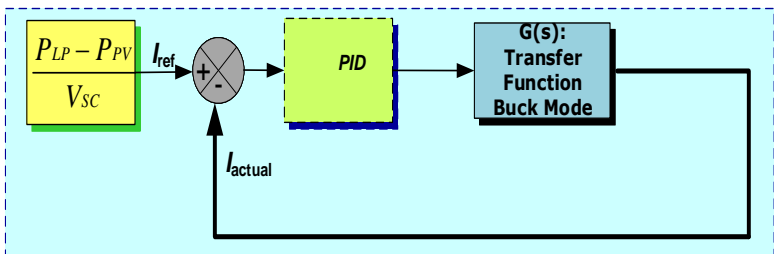

(a)

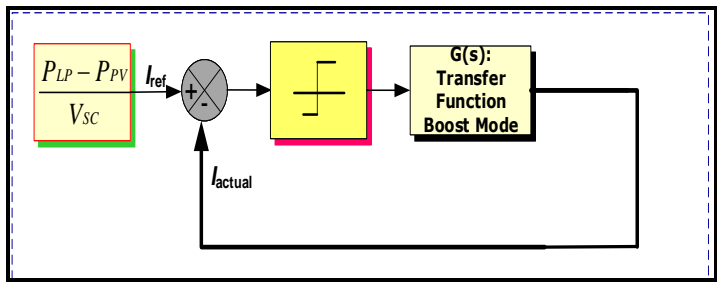

(b)

Figure 4a. Constant Current Charging Method; 4b. Constant Current Discharging Method

\subsection{Proposed Sliding Mode Control}

Multi loop controllers gives superior results in terms of better system stability and transient performance, hence in voltage controlled inverters, it is always good to consider the inner current loop also. In the proposed SMC the current error derived from the error in voltage is used in the inner loop while the voltage error control is used in the outer loop. The Sliding Mode Controller operates at very high switching frequency and in such a way that the capacitor output voltage $V_{C}$ and the input inductor current $i_{L}$ track precisely their respective reference values.

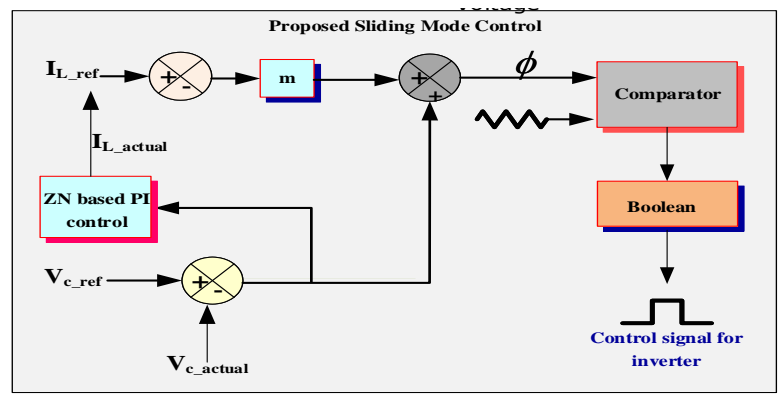

Figure 5. Proposed Control Scheme

To get global stability, instead of considering direct voltage and current variables, their respective errors are taken as state variables. The proposed sliding surface is a linear combination of such state variable. 


$$
\varphi=V_{\text {error }}+m I_{\text {error }}
$$

where $V_{\text {error }}=V_{\text {Cref }}-V_{C}, I_{\text {error }}=i_{\text {Lref }}-i_{L 1}$ and $m=$ sliding coefficient

The controller consists of inductor current $i_{L 1}$ and output voltage $V_{C 2}$ feedback.

$$
i_{\text {Lref }}=\left(k_{p}+\frac{k_{i}}{s}\right)\left[V_{\text {Cref }-} V_{C}\right]
$$

where $\mathrm{K}_{\mathrm{P}}$ is proportional constant and $\mathrm{K}_{\mathrm{i}}$ is integral constant of the PI controller.

When SMC controller drives the VSI towards the singular point, it makes

$$
\varphi=0
$$

Equating $\varphi=0$ in equation (1), $0=V_{\text {error }}+m I_{\text {error }}$

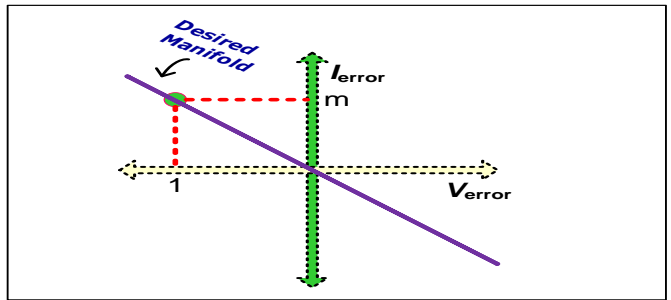

Figure 6. Proposed Sliding Plane

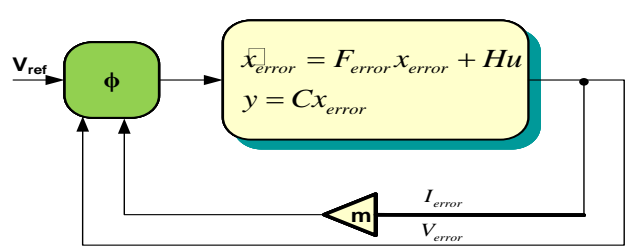

Figure 7. Closed Loop Control Model of Proposed System

Therefore,

$$
V_{\text {error }}=-m I_{\text {error }}
$$

From closed loop model control effort can be realized as

$$
\begin{aligned}
& u=V_{\text {error }}+m I_{\text {error }} \\
& u=\left[\begin{array}{ll}
1 & m
\end{array}\right]\left[\frac{V_{\text {error }}}{I_{\text {error }}}\right]
\end{aligned}
$$

Without loss of generality according to state feedback method

$$
u=-k x_{\text {error }}
$$

Comparing equation (6) and (7)

$$
k=\left[\begin{array}{ll}
1 & m
\end{array}\right]
$$


As a result of new error state variables the state space representation of VSI system can be represented as:

$$
\begin{aligned}
& \underset{\text { error }}{\mathbb{\&}}=F_{\text {error }} x_{\text {error }}+H u \\
& y=C x_{\text {error }}
\end{aligned}
$$

The value of $F_{\text {error }}$ is obtained as follows [5]

$$
F_{\text {error }}=\left[I-H(k H)^{-1} u\right] F
$$

From equation (10):

$$
F_{\text {error }}=\left(\begin{array}{cc}
-\frac{1}{Z C} & \frac{1}{C} \\
\frac{1}{m Z C} & -\frac{1}{m C}
\end{array}\right)
$$

Keeping value of (7) in (8)

$$
\begin{aligned}
& \mathbb{e r r o r}_{\text {error }}^{x_{\text {error }}}+H\left(-k x_{\text {error }}\right) \\
& \&_{\text {error }}=\left[F_{\text {error }}-H k\right] x_{\text {error }}
\end{aligned}
$$

Let $F^{\prime}$ be denoted by $\left[F_{\text {error }}-H k\right]$

The value of sliding coefficient $m$ can be calculated in form of Eigen values as

$$
\begin{aligned}
& {\left[\lambda I-F^{\prime}\right]=0} \\
& \left(\begin{array}{cc}
\lambda+\frac{1}{Z C} & -\frac{1}{C} \\
\frac{1}{m Z C}+\frac{V_{D C}}{L} & \lambda+\frac{1}{m C}+\frac{m V_{D C}}{L}
\end{array}\right)=0 \\
& \lambda^{2}+\frac{\lambda}{m C}+\frac{\lambda m V_{D C}}{L}+\frac{\lambda}{Z C}+\frac{m V_{D C}}{L Z C}+\frac{V_{D C}}{C}=0
\end{aligned}
$$

The value of $m$ can be obtained by comparing the above equation with the characteristics equation of desired system where $T_{s}=1 \times 10^{-4} \mathrm{sec}, \xi=0.8$

Then from $T_{s}=\frac{3}{\xi \omega_{n}}, \omega_{n}=3.75 \times 10^{4}$

Then from standard second order system characteristics equation $s^{2}+2 \xi \omega_{n} s+\omega_{n}{ }^{2}=0$

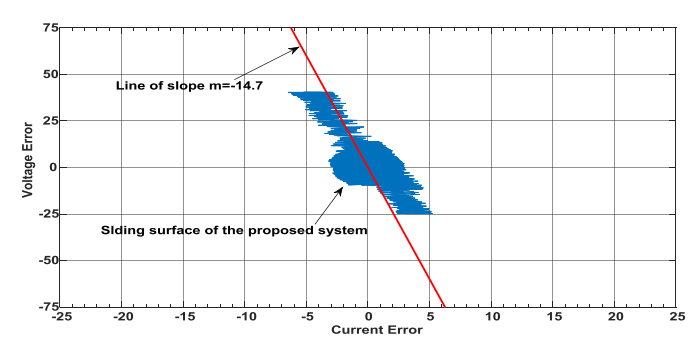

Figure 8. Simulation Result of Sliding Plane of Proposed System 
Characteristics equation of the desired system becomes

$$
\lambda^{2}+\left(6 \times 10^{4}\right) \lambda+\left(3.75 \times 10^{4}\right)^{2}=0
$$

Substituting values specified below in equation (16) and comparing with equation (17) will yield sliding mode coefficient $m=14.7$.

The parameters of the system used for simulation results are $V_{D C}=500 \mathrm{~V}, \mathrm{Z}=528 \Omega, L=1 \mathrm{mH} . \mathrm{C}=100 \mu \mathrm{F}$ Now the Eigen values obtained by

$$
\begin{aligned}
& {\left[\lambda I-F_{\text {error }}\right]=0} \\
& \left(\begin{array}{cc}
\lambda+\frac{1}{Z C} & -\frac{1}{C} \\
\frac{1}{m Z C} & \lambda+\frac{1}{m C}
\end{array}\right)=0 \\
& \lambda^{2}+\frac{\lambda}{m C}+\frac{\lambda}{Z C}=0
\end{aligned}
$$

By taking sliding coefficient as $m=14.7$ as calculated above Eigen values of comes out to be $\lambda_{1}=0, \lambda_{2}=-69.9$. Therefore it is clearly seen that the Eigen values obtained will always be located on the left-half of the s-plane denoting the system stability.

\section{RESULTS AND DISCUSSION}

Figure 9 represents the simulation of the proposed system with SMC and PI fed VSI for non linear Load. The simulations are performed with PV panel as primary energy source giving DC voltage of 250 Volt. The PV parameters considered here for Solar Irradiation of $1000 \mathrm{~W} / \mathrm{m}^{2}$ are $V_{o c}=64 X 4=256 \mathrm{~V}, I_{s c}=6.14 \mathrm{~A}, I_{m p p}$ $=5.76 \mathrm{~A}, V_{m p p}=54.7 \mathrm{~V}$. This PV voltage is boosted up with the help of MPPT controlled boost converter which gives the output around 500Volt DC. Here solar irradiation is varied at particular intervals. The PV panel is initially given irradiation of $1000 \mathrm{~W} / \mathrm{m}^{2}$. It is increased to $1200 \mathrm{~W} / \mathrm{m}^{2}$ and reduced to $500 \mathrm{~W} / \mathrm{m}^{2}$ at $0.5 \mathrm{sec}$ and $0.85 \mathrm{sec}$ respectively. This results in the variation of PV output voltage. In addition to the variation of irradiation, the load power is also varied in order to study the stability of the system in the presence of load disturbances. By connecting a parallel RL load in existing load, the load power is raised from $2500 \mathrm{~W}$ to $3000 \mathrm{~W}$ and brought back to $2500 \mathrm{~W}$ at $0.24 \mathrm{sec}$ and $0.35 \mathrm{sec}$ respectively, with this a reference power is made and actual power is compared in the upcoming waveforms. The output voltage of PV panel as seen by the DC link changes with change in irradiation, where the supercapacitor, having output of $250 \mathrm{~V}$, managed by its charge controller (bidirectional buck boost converter): acts to maintain a constant output voltage of $500 \mathrm{~V}$ at the DC link.

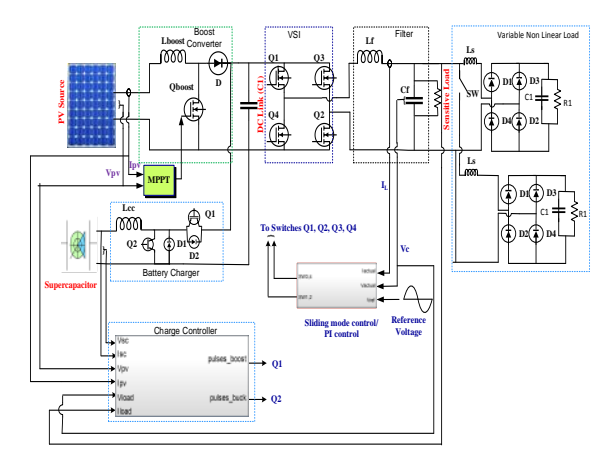

Figure 9. Multistage Converter with SMC PI Controlled Inverter for Nonlinear Load 
The reference capacitor voltage is considered as $325 \sin \omega t$. The load current is multiplied by 2 for the purpose of clarity. The inductor current is obtained by passing error capacitor voltage through PI Controller, whose $\mathrm{Kp}$ and $\mathrm{Ki}$ values are evaluated through $\mathrm{Z}-\mathrm{N}$ based technique.

\subsection{Performance Analysis of PV Fed Multi Stage Converter with PI Controlled VSI for Non Linear Load}

Simulation results shown in Figure 10 reveal that the irradiation based changes in PV output (Figure $10 \mathrm{a}(\mathrm{c})$ ) are effectively complimented by the supercapacitor Figure 10a (b) to meet the load variation Figure 10a (a). The increased load power between $0.24 \mathrm{sec}$ to $0.34 \mathrm{sec}$ as shown in Figure 10a (a) is met by supercapacitor as shown by Figure 10a (b) with the help of its charge controller (buck-boost converter). It is clear from Figure 10a (a), (b), (c) that an increase in load power in the interval of $0.24 \mathrm{sec}$ to $0.34 \mathrm{sec}$ is exclusively met by the supercapacitor and not by the PV source. Figure 10a (d) corroborates this fact by showing a decreasing SOC in this duration. Further the irradiation is increased from $1000 \mathrm{~W} / \mathrm{m} 2$ to 1200 $\mathrm{W} / \mathrm{m} 2$ at $0.5 \mathrm{sec}$ and decreased from $1200 \mathrm{~W} / \mathrm{m} 2$ to $500 \mathrm{~W} / \mathrm{m} 2$ at $0.85 \mathrm{sec}$.

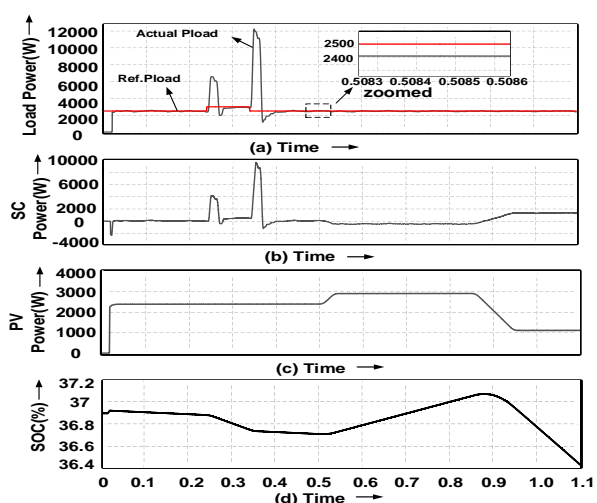

(a)

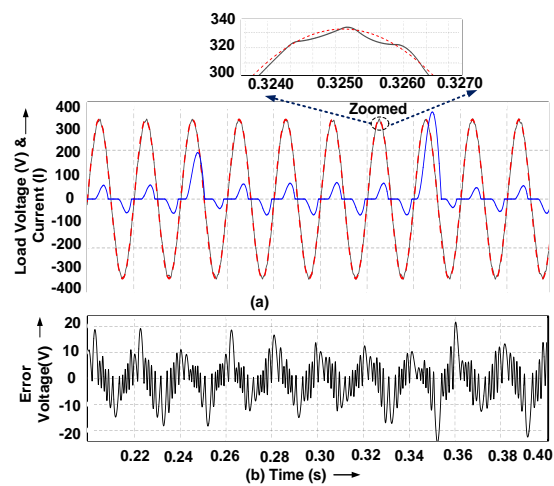

(b)

Figure 10a. Output Load Power, SC Power and PV Power for PI Controlled VSI. 10b. PI Controlled VSI Output Voltage Waveform Showing Error $=21.54 \mathrm{~V}$

Figure 10a (b) and Figure 10a (c), (d) shows that the supercapacitor gets charged (by buck action of buck boost converter) in the interval from $0.5 \mathrm{sec}$ to $0.85 \mathrm{sec}$ from PV panel such that a constant power of $2500 \mathrm{~W}$ is maintained across the load similarly from $0.85 \mathrm{sec}$ to $1.1 \mathrm{sec}$ the PV output is reduced and the supercapacitor discharges (by boost action of buck boost converter) to maintain a constant power supply to the load. The initial dip in power output of supercapacitor is attributed to the initial charging of the supercapacitor. Further the initial delay in the output power from PV array is due to the time taken by PV array to generate maximum power of $2500 \mathrm{~W}$. The zoomed part of load power waveform in Figure 10a (a) shows the difference between reference load power and the actual load power is 100 Watt. This difference remains throughout up to $1.1 \mathrm{sec}$. There are two spikes visible at the instant of load variation in the waveform at $0.24 \mathrm{sec}$ and $0.34 \mathrm{sec}$. It is due to the presence of instant charging of capacitor in the nonlinear load.

Figure 10b (a) shows the actual output capacitor voltage, reference voltage waveforms, and the current waveform, Figure $10 \mathrm{~b}$ (b) shows its error voltage waveform which has error of 21.54 Volt. The THD in the output voltage of PI controlled VSI is $2.17 \%$.

\subsection{Performance Analysis of PV Fed Multi Stage Converter with SMC Controlled VSI for Non Linear Load}

Figure 11a reveals that on changing the load the load power settles to reference power with a difference of only $4 \mathrm{Watts}$ in a few milliseconds only. Figure $11 \mathrm{~b}$ shows the tracking of voltage across capacitor to its reference voltage along with the error voltage which is equal to 1.2 Volt. 


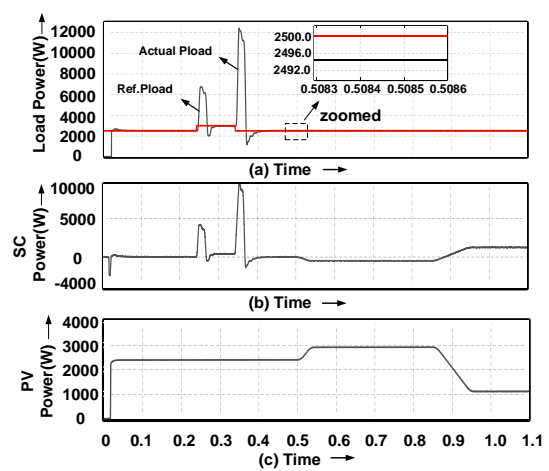

(a)

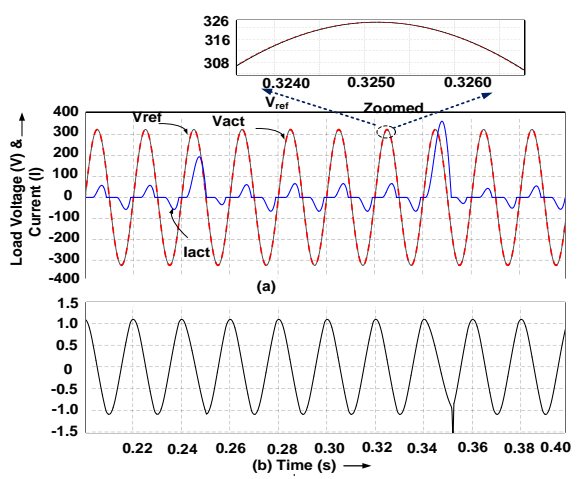

(b)

Figure 11a. Output Waveforms of Load Power, SC Power and PV Power for SMC Controlled VSI 11b. SMC Controlled VSI Output Voltage Waveform Showing Error $=1.2$ Volts

The zoomed portions of Figure $10 \mathrm{~b}$ and Figure $11 \mathrm{~b}$ show that tracking of capacitor voltage to its reference voltage matches perfectly with Sliding Mode Controller as against the PI controller in nonlinear load.The THD performance of VSI deploying SMC is $0.25 \%$

\subsection{Comprehensive Analysis of Findings}

The impact of improved (SMC) controller in the performance of multistage converter system is assist in terms of THD, $\mathrm{V}_{\text {error }}(\max )$, steady state error in power and peak of fundamental component of output voltage is shown in Table 1.

Table 1. Comparative Table

\begin{tabular}{ccc}
\hline Type of Multistage System & SMC controlled VSI for Non-linear load & PI controlled VSI for Non-linear load \\
\hline THD & $0.25 \%$ & $2.17 \%$ \\
Verr (max) & $1.3 \mathrm{~V}$ & $21.54 \mathrm{~V}$ \\
Steady state error in Power & $4 \mathrm{~W}$ & $100 \mathrm{~W}$ \\
Fund Component of Voltage & 325 & 320.5 \\
\hline
\end{tabular}

\section{CONCLUSION}

A novel approach comprising of the integration of multistage converter system deploying MPPT with boost converter, PI / SMC controllers with VSI for nonlinear loads has been carried out. The analysis of performance of PV fed multistage converter system deploying SMC controlled VSI shows that both the THD as well as the output-voltage-error are less in comparison to those obtained with the conventional PI controlled VSI under identical loading conditions. Also it is found that the steady state error between the power demand and supply is very high with PI controllers. Thus the SMC Controlled VSI used with MPPT controlled PV generation can be a superior option for integrating it to the micro grid systems. Further it was interesting to note that the controllers take due care of satisfactorily integrating the supercapacitor to compensate the intermittency of PV source.

\section{REFERENCES}

[1] Satish Kumar Gudey, Rajesh Gupta, "Second Order Sliding Mode Control for a Single Phase Voltage Source Inverter, IET Power Electronics 2014

[2] Abdel-Rahim, N.M., Quaicoe, J.E.: 'Analysis and design of a multiple feedback loop control strategy for singlephase voltage-source UPS inverters', IEEE Trans. Power Electron., 1996, 11, (4), pp. 532-541

[3] Ortega, R., Loria, A., Nicklasson, P.J., Sira-Ramirez, H.: 'Passivity-based control of Euler-Lagrange systems' (New York, Springer-Verlag, 1998)

[4] Marquez, H.J.: 'Nonlinear control systems: analysis and design' (John Wiley \& Sons, 2003)

[5] Gudey, S.K., Gupta, R.: 'Sliding mode control in voltage source inverter based higher order circuits', Int. J. Electron., 2015, 102, (4), pp. 668-689 
[6] Utkin, V.I.: 'Variable structure systems with sliding modes', IEEE Trans. Autom. Control, 1977, 22, (2), pp. 212222

[7] Pmheiro, H., Martins, A.S., Pinheiro, R.: 'A sliding mode controller in single phase voltage source inverters'. Proc. IEEE IECON, Bologna, September 1994,pp. 394-398

[8] Tai, T.L., Chen, J.S.: 'UPS inverter design using discrete-time sliding - mode control scheme', IEEE Trans. Power Electron., 2002, 18, (1), pp. 67-75

[9] Suwat Sikkabut,et all Control strategy of solar/wind energy power plant with supercapacitor energy storage for smart DC microgrid, 2013 IEEE 10th International Conference on Power Electronics and Drive Systems (PEDS)

[10] A. S.Weddell, G. V.Merrett, T. J. Kazmierski, and B. M. Al-Hashimi,“Accurate supercapacitor modeling for energy harvesting wireless sensor nodes,” IEEE Trans. Circuits Syst. II, Exp. Brief, vol. 58, no. 12, pp. 911-915, Dec. 2011.

[11] Zhongqiu Wang; Xi Li; Gengyin Li; Ming Zhou; K L Lo "Energy storage control for the Photovoltaic generation system in a micro-grid" 2010 5th International Conference on Critical Infrastructure (CRIS) 